\title{
CADASIL: a guide to a comparatively unrecognised condition in psychiatry
}

\author{
Mark H. Taylor \& Gillian A. Doody
}

Abstract This guide to the neurological disorder cerebral autosomal dominant arteriopathy with subcortical infarcts and leucoencephalopathy (CADASIL) is specifically targeted at psychiatrists. The aims are to enhance awareness, provide educational clinical information and offer practical guidance on management of the disorder. An overview of diagnostic algorithms and recent research is also provided.

Cerebral autosomal dominant arteriopathy with subcortical infarcts and leucoencephalopathy (CADASIL) is a disorder that has received attention in the neurological literature, but remains relatively unknown within clinical or academic psychiatry (Kessing, 2005). This is surprising as it may present to the adult or old age psychiatrist. The prevalence of CADASIL appears to be about 2 per 100000 (about 1200 people with the condition in the UK). This may be an underestimate as the disorder is thought to be misdiagnosed, particularly in areas where cardiovascular disease and multiple sclerosis are highly prevalent. It has also only recently been characterised (Razvi et al, 2005). By comparison, Huntington's disease, a condition highlighted in the Royal College of Psychiatrists' Membership (MRCPsych) curriculum, has a prevalence of 5 per 100000 (about 3000 people in the UK) (Kumar \& Clark, 2005). Although CADASIL is currently untreatable, referral of suspected cases is important, to allow diagnosis and specialist care to be provided. There are significant prognostic implications for the individual and members of their present and future families.

\section{What is CADASIL?}

In 1977 Sourander \& Walinder proposed a hereditary form of multi-infarct dementia characterised by recurrent strokes and cognitive impairment. At around the same time, Stevens described a disorder in an English family with chronic vascular encephalopathy. A clinical phenotype of migraine and recurrent strokes was observed later in French family members. This became known as CADASIL (Kalaria et al, 2004). It was mapped to chromosome 19p13 by Tournier-Lasserve (Dichgans et al, 1998). Linkage was later confirmed in a large number of families (Dichgans et al, 1998), and Joutel et al (1997) found the human Notch3 gene to be the CADASIL critical region.

CADASIL is a pure form of white matter ischaemic disease. There is a $60-70 \%$ reduction in choline acetyltransferase in cortical regions. This is suggestive of significant cholinergic dysfunction (Keverne et al, 2006). There is evidence that axons in the parieto-occipital and dorsal frontal cortex are damaged (Mesulam et al, 2003).

\section{How does it present?}

The clinical presentation of CADASIL is variable (for examples see Boxes 1 and 2). Onset is usually at a young age (mean: $35-40$ years) but there is a potentially wide variation (range: $20-70$ years). The initial presentation is primarily with neurological features of stroke (a third of cases) or migraine (a third of cases). Migraine (usually accompanied by aura) is particularly common in younger patients. Recurrent episodes of stroke or transient ischaemia occur in $70 \%$ of cases. Lacunar infarcts are predominant, causing right or left hemiplegia. Psychiatric manifestations are the initial presentation in $15 \%$ of CADASIL cases. These includes depression, behavioural disturbance and dementia syndromes. The disease tends to follow a step-wise deterioration, although it can be insidious (Davous, 1998).

Mark Taylor is a specialist registrar in forensic psychiatry with North Nottinghamshire Community Forensic Service (Forest House, The Forest, Southwell Road West, Mansfield NG18 4HH, UK. Email: taylors@doctors.org.uk). His particular interest is in organic clinical presentations. Gillian Doody is Clinical Associate Professor and an honorary consultant psychiatrist with the Division of Psychiatry, University of Nottingham, UK. 
Box 1 Diagnosis following severe depressive episode

A 55-year-old man had developed blurred vision followed by bi-frontal headache at the age of 20 (indicative of migraine with aura). Later in life he experienced depressive and hypomanic episodes, which required acute psychiatric hospitalisation. On one occasion he was admitted following a significant suicide attempt. His presentation on admission was melancholic, with nihilistic thinking and a paucity of speech. There was no family history of note. He had no vascular risk factors. On physical examination he was normotensive, and the only notable finding was of left-sided hyperreflexia. On cognitive testing there was evidence of oral perseveration, imitation behaviour, deficit in recall and reduced verbal fluency. Magnetic resonance imaging revealed well-delineated lesions in the left basal ganglia region. He responded well to psychotropic treatment and was discharged after 3 months of in-patient treatment.

\section{Psychiatric presentation}

Psychiatric symptoms are seen in $30 \%$ of patients with a diagnosis of CADASIL. Mood disorders, stress-related (adjustment) disorders and subcortical dementia are the most frequent forms of psychiatric disorder (Dichgans et al, 1998). Table 1 highlights the differences in presentation when comparing CADASIL with other forms of dementia and with relevant functional illnesses.

\section{Box 2 Diagnosis following personality and behavioural change}

A 65-year-old woman was admitted to a day hospital for assessment after her family reported concerns about personality change, poor self-care and overall behavioural decline. Her daughter disclosed a history of migraines. The woman became irritable when questioned, but there was no evidence of psychotic symptoms on mental state examination. She was disoriented in time and place, and had poor short-term recall. Her gait was short-stepped and slow. There was evidence of primitive reflexes. Magnetic resonance imaging revealed diffuse, confluent increase in $T_{2}$-weighted images. She died within 6 months of diagnosis of CADASIL being made, having progressed to end-stage dementia.

\section{Mood disorders}

A depressive episode will occur in $8 \%$ of those who develop CADASIL. For 6\% it will be the initial presentation (Davous, 1998). It may also develop later, as a complication of stroke or as a consequence of the psychosocial impact of CADASIL diagnosis. Depression tends to be more likely to occur later in the course of the disease (Desmond et al, 1999). This is in the context of depression occurring in a third of the general stroke population (Spalletta et al, 2006).

There is considerable research interest in the relationship between vascular disease and depression. Hypotheses have emerged linking aetiology and clinical presentation, such as 'vascular depression' and 'post-stroke depression'. Alexopoulos et al (1997) proposed that late-onset depression associated with vascular risk factors is characterised by a particular symptom cluster (cognitive dysfunction, disability, psychomotor retardation, lack of insight and limited depressive ideation). Disruption of key prefrontal neural pathways by white matter hyperintensities (ischaemic lesions) is thought to play a role in pathogenesis. Post-stroke depression is a related concept in which axonal damage and cytokine activity are thought to affect serotonin metabolism, thereby inducing depression (Spalletta et al, 2006). It may be that these mechanisms are pertinent in CADASIL.

Psychotic mood disorders were noted in 35\% of people with CADASIL in one small study (Verin et al, 1995), although such a high proportion has not been replicated in later studies. Correlations were noted in terms of age, clinical features and neuroimaging results. The study authors speculated that the CADASIL gene may be a candidate gene for familial forms of bipolar disorder. Manic episodes have rarely been documented otherwise (Dichgans et al, 1998; Desmond et al, 1999).

In a larger case series, adjustment disorder was noted to represent most cases of mood disorder. It is apparent, however, that they should be formally categorised among the neurotic, stress-related and somatoform disorders in ICD-10. No further subclassification was given but in terms of aetiology it was suggested that these developed in reaction to 'non-psychiatric disease manifestations' (Dichgans et al, 1998).

\section{Dementia syndrome}

Cognitive impairment amounting to a dementia syndrome occurs in about half of people with CADASIL. Of these, 6-10\% will have dementia at the onset of the disease. After 10 years of disease evolution, at least $50 \%$ of CADASIL patients will have exhibited motor deterioration, pseudobulbar signs and dementia 
Table 1 Differences in presentation comparing other forms of dementia, CADASIL and functional illnesses

\begin{tabular}{|c|c|c|c|}
\hline & Other dementias ${ }^{1}$ & CADASIL & Functional illness ${ }^{2}$ \\
\hline Epidemiology & $\begin{array}{l}\text { More common, especially } \\
\text { Alzheimer's and vascular } \\
\text { dementia }\end{array}$ & Very rare & $\begin{array}{l}\text { More common: especially } \\
\text { depression }\end{array}$ \\
\hline Age at onset & $\begin{array}{l}\text { FTD: early (40s) } \\
\text { Others: } 60 \text { s usually; prior stroke } \\
\text { is key in vascular dementia }\end{array}$ & Very early (can be late teens) & $\begin{array}{l}\text { Usually early: especially psychosis } \\
\text { Later peaks with physical illness } \\
\text { onset, in terms of affective } \\
\text { disorder }\end{array}$ \\
\hline $\begin{array}{l}\text { Associated/ } \\
\text { predisposing } \\
\text { factors }\end{array}$ & $\begin{array}{l}\text { Family history important } \\
\text { Early-form Alzheimer's: } \\
\text { autosomal dominant } \\
\text { Vascular dementia: vascular risk } \\
\text { factors }\end{array}$ & $\begin{array}{l}\text { Autosomal dominant } \\
\text { inheritance with variable } \\
\text { penetration }\end{array}$ & $\begin{array}{l}\text { Life events important; } \\
\text { vulnerability; neurodevelopmental } \\
\text { hypothesis in schizophrenia }\end{array}$ \\
\hline $\begin{array}{l}\text { Clinical } \\
\text { features }\end{array}$ & $\begin{array}{l}\text { Alzheimer's: recent memory } \\
\text { loss occurs early during decline, } \\
\text { visuospatial skill deficits, } \\
\text { dysphasia and dyspraxia } \\
\text { FTD: hyperorality, stereotyped } \\
\text { and perseverative behaviour; } \\
\text { primitive reflexes evident early } \\
\text { in disease } \\
\text { Vascular dementia: memory } \\
\text { deficit less severe than in } \\
\text { Alzheimers'; insight often } \\
\text { preserved until late, periods of } \\
\text { confusion (micro-infarcts) }\end{array}$ & $\begin{array}{l}\text { Migraine, with aura: can be sole } \\
\text { initial symptom manifestation } \\
\text { Affective symptoms: depressive } \\
\text { or hypomanic } \\
\text { Early or later in clinical } \\
\text { presentation: cognitive deficits } \\
\text { in executive functioning, } \\
\text { memory; frontal lobe symptoms; } \\
\text { amotivation } \\
\text { Established disease: pseudo- } \\
\text { bulbar signs, dysarthria, } \\
\text { dysphagia, incontinence, extra- } \\
\text { pyramidal signs such as tremor } \\
\text { and rigidity }\end{array}$ & $\begin{array}{l}\text { No evidence from CADASIL } \\
\text { families suggests that symptoms } \\
\text { of clinical presentation is different } \\
\text { from functionally derived illness } \\
\text { Melancholic depressive picture } \\
\text { appears more evident in } \\
\text { CADASIL } \\
\text { Only features that may indicate } \\
\text { organic basis: extremely early } \\
\text { or late onset, co-existing } \\
\text { migraine, illness unresponsive to } \\
\text { psychotropic treatment }\end{array}$ \\
\hline Neuroimaging & $\begin{array}{l}\text { Alzheimer's: ventricular } \\
\text { dilatation; cortical atrophy } \\
\text { FTD: selective frontal and } \\
\text { temporal atrophy } \\
\text { Vascular dementia: extensive } \\
\text { white matter lesions; infarcts } \\
\text { may be present }\end{array}$ & $\begin{array}{l}\text { Cortical high signal on } T_{2} \text { or } \\
\text { FLAIR in subcortical areas and } \\
\text { basal ganglia }\end{array}$ & $\begin{array}{l}\text { No consistent findings diagnostic } \\
\text { of affective disorder or } \\
\text { schizophrenia }\end{array}$ \\
\hline $\begin{array}{l}\text { Course of } \\
\text { disease, } \\
\text { prognosis }\end{array}$ & $\begin{array}{l}\text { Alzheimer's and FTD: insidious } \\
\text { decline } \\
\text { Vascular dementia: abrupt onset, } \\
\text { then step-wise progression }\end{array}$ & $\begin{array}{l}\text { Disease progresses to end-stage } \\
\text { features, as described, after } 10 \\
\text { years }\end{array}$ & $\begin{array}{l}\text { Dependent on genetic factors, } \\
\text { insight, treatment adherence, } \\
\text { psychosocial supports }\end{array}$ \\
\hline Treatment & $\begin{array}{l}\text { Alzheimer's disease: AChE } \\
\text { inhibitors } \\
\text { FTD, vascular dementia: no } \\
\text { specific treatments } \\
\text { Vascular dementia: manage risk } \\
\text { factors }\end{array}$ & $\begin{array}{l}\text { May be a role for AChE } \\
\text { inhibitors; treat affective/ } \\
\text { psychotic symptoms as if } \\
\text { functionally derived }\end{array}$ & $\begin{array}{l}\text { Treat according to diagnosis, } \\
\text { chronicity, severity, adherence, } \\
\text { comorbid physical disorder }\end{array}$ \\
\hline
\end{tabular}

(Davous, 1998). Behavioural disturbance and frontal lobe symptoms such as euphoria, inattention and impulsivity have been described in about a third of the dementia subgroup (Desmond et al, 1999).

\section{Other psychiatric disorders}

Findings from large case series suggest that nonaffective psychotic illness is rare in CADASIL.
Schizophreniform illness and persistent delusional disorder appear to be extremely rare, although a case of CADASIL with schizophrenia has been described (Lagas \& Juvonen, 2001). There are case reports of post-partum psychosis (Pantoni et al, 2005), agoraphobia and alcohol dependence (Leyhe et al, 2005) in the literature. Six cases out of seventy in a British CADASIL prevalence study had an acute encephalopathy which was misdiagnosed as viral 


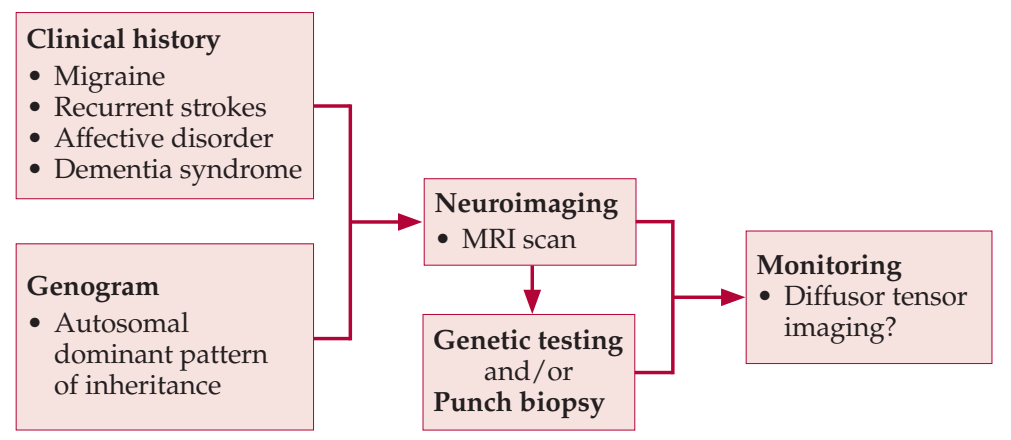

Fig. 1 Suggested pathway for the diagnosis of CADASIL.

encephalitis. They all had a history of migraine with aura (Schon et al, 2003).

\section{Making a diagnosis}

Figure 1 shows a pathway for diagnosing CADASIL.

\section{Neuroimaging}

On magnetic resonance imaging (MRI) there is cortical high signal on $T_{2}$-weighted or FLAIR (fluidattenuated inversion recovery) sequences in the periventricular white matter, basal ganglia, thalamus, internal capsule and pons (Kalaria et al, 2004). Hyperintensities of the external capsule are radiological markers for CADASIL. Involvement of the anterior pole of the temporal lobe is a characteristic finding (O'Sullivan et al, 2001). Radiological penetrance appears to be complete by the age of 35, significantly earlier than the full clinical syndrome may be manifest.

Lesion load on MRI seems to be correlated with some clinical features, including stroke and dementia. Depression is more commonly seen in those with white matter hyperintensities (Singhal et al, 2005).

Ultrastructural tissue damage can be detected by performing histograms of the mean diffusivity of the brain, using diffusor tensor imaging (DTI). This is a technique whereby the tissue architecture can be investigated in terms of water molecule displacement. Diffusor tensor imaging may have a role in tracking and predicting the extent of clinical disease progression in CADASIL. Imaging results may in future be used as outcome measures in therapeutic trials (Holtmannspotter et al, 2005).

\section{Genetics}

CADASIL follows an autosomal dominant Mendelian mode of inheritance with variable penetrance. The Notch3 gene of chromosome 19 has been identified as the CADASIL critical region. Notch3 encodes a transmembrane receptor which has a crucial role within vascular smooth muscle signalling pathways. It is comprised of 33 exons. The distribution of mutations in the gene differs between countries. In the UK prevalence study $73 \%$ of mutations were found to be at exon 4 (Markus et al, 2002). Although selective screening will detect the majority of cases some will still be missed. Notch3 is a large gene and screening for all of the exons is clinically impracticable (S. Singhal, personal communication, 2007). There are also associated financial implications (Hugh Markus, personal communication, 2007). Gene testing can be performed on a peripheral blood sample.

There may be genetic modifying factors that influence individual differences in lesion load on MRI. This would account for the variety of phenotypic expression of CADASIL, even within the same family (Opherk et al, 2006).

\section{Histopathology}

Punch skin biopsy using immuno-staining techniques can assist in the diagnosis of CADASIL. The alternative is to use electron microscopy to identify characteristic glomerular osmiophilic material (GOM) in the smooth muscle vasculature of arterioles (Markus et al, 2002). Local clinical practice is to perform skin biopsy in gene-negative cases as this may detect a further small percentage of cases (S. Singhal, personal communication, 2007).

\section{Difficulties in diagnosis}

Other causes of leucoencephalopathy (demyelination of white matter of the cerebral hemispheres) include the following (Kumar \& Clark, 2005).

- Sporadic small-vessel vascular disease, usually accompanied by hypertension.

- Multiple sclerosis, a chronic inflammatory disease of the central nervous system in which 
multiple plaques of demyelination are distributed within the brain and spinal cord. A reaction mediated by $\mathrm{CD} 4$ cells occurs against myelin.

- Other inflammatory conditions, including cerebral vasculitis and systemic lupus erythematosis. These can be difficult to diagnose and the appropriate auto-antibody testing should be performed.

- Infections such as HIV and varicella zoster virus. These can result in cerebral destruction due to viral accumulation in brain tissue, leading to a progressive multifocal leucoencephalopathy.

- Even rarer causes involve damage due to toxic or metabolic effects, for example heavy metal poisoning, illicit drug use (ecstasy or cocaine) and immunosuppressant agents.

\section{Whom to suspect?}

- Those with a personal or family history of any neurological disorder, but notably migraine (especially if accompanied by aura), epilepsy, stroke or transient ischaemic event, coma, dementia, multiple sclerosis, meningitis, encephalitis or vasculitis. The latter four of these can be common misdiagnoses of the clinical presentation of CADASIL.

- There are no distinctive clinical examination findings in CADASIL.

- However, patients with abnormal computed tomography (CT) scan findings should be considered. A CT may detect some changes but MRI is required for definitive imaging.

\section{What to do next?}

- Careful medical and psychiatric history-taking with the aid of informants is important. The compilation of a genogram will highlight patterns of inheritance.

- Blood samples: full blood count, inflammatory markers, vasculitis screen, auto-antibodies, clotting studies, clinical chemistry, lipids, syphilis serology, viral serology (to exclude other potential differential diagnoses).

- Electrocardiogram (ECG) and chest X-ray (for indications of cardiovascular disease).

- Neuroimaging: preferably MRI.

- Manage as if the patient were suspected of having a vascular dementia. Consider guidance regarding prescription of psychotropic drugs (see 'Psychiatric management').

- Refer to a local neurologist, preferably with an interest in stroke.

\section{Treatment and prognosis}

\section{Secondary prevention: general medical management}

There is no evidence to support the use of specific treatments to influence the progression of ischaemia in CADASIL. The mainstay of current medical management is to address risk factors for stroke (Kumar \& Clark, 2005):

- antiplatelet therapy: a combination of aspirin and dipyridamole is regarded as probably the optimal prophylaxis against further thromboembolic stroke

- aggressive treatment of hypertension with antihypertensives

- statin therapy: reduces cerebrovascular disease by a third, even if not hypercholesterolaemic

- detection and management of diabetes mellitus

- lifestyle factors: weight reduction, regular and beneficial forms of exercise, smoking cessation, controlled alcohol intake

- treatment of comorbid pathology, for example valvular heart disease.

There is emerging evidence regarding the role of vascular risk factors in the disease process. Cerebral microhaemorrhages have been independently associated with hypertension and poor glycaemic control, as well as with lacunar infarcts and white matter intensities (Viswanathan et al, 2006). It may be that vascular risk factors play a role in exacerbating damage to cerebral vessels caused by Notch3 mutation (Singhal et al, 2004).

Vasculotropic agents such as pentoxifylline have been used in multi-infarct dementia. There is no evidence to support their use in the CADASIL population.

Symptomatic relief of migraine involves using a prophylactic agent, although care must be taken about vasoconstrictive effects.

\section{Psychiatric management}

Psychotropic drugs for mental illness in CADASIL

Patients with CADASIL that present with affective disorder or psychosis appear to respond to treatment protocols that would be consulted in functional illness (for example Maudsley prescribing guidelines; Taylor et al, 2007). This experience appears to be anecdotal, as no specific studies have looked at this issue (Leyhe et al, 2005). It would seem appropriate to consider CADASIL as stroke when considering psychotropic drug prescription. The evidence base on the use of antidepressants post-stroke and for 
patients with comorbid medical problems is mainly in favour of selective serotonin reuptake inhibitors (SSRIs). It is advised that they are commenced at a low dose and titrated slowly (Kennedy \& Marcus, 2005). Tricyclic antidepressants are best avoided if possible (Davies et al, 2004).

\section{Acetylcholinesterase inhibitors}

There is evidence of cholinergic dysfunction in CADASIL, and there may be a role for acetylcholinesterase inhibitors in relief of symptoms of the disorder. A multicentre, 18-week, placebo-controlled, double-blind, randomised parallel-group trial into whether donepezil improves cognition in patients with CADASIL has recently been published. This was a comparatively large study (involving 168 participants). Donepezil had no effect on cognition as measured by the V-ADAS-cog scoring tool (Dichgans et al, 2008). Elsewhere, the Paris-Munich research collaboration (Box 3), which represent a significant body of the world literature on CADASIL, is pioneering research into future treatments.

European guidance suggests prescribing donepezil for mild to moderate vascular dementia (Waldemar et al, 2007). However, National Institute for Health and Clinical Excellence (NICE) guidance in the UK does not support such prescription. Indeed it permits acetylcholinesterase inhibitors to be prescribed only in moderate Alzheimer-type dementia (National Collaborating Centre for Mental Health, 2006).

Behavioural and psychological symptoms in CADASIL dementia

Behavioural and psychological symptoms may emerge during the progression of dementia. The European and the NICE guidelines share the expectation that non-pharmacological approaches will be taken first. This may involve psychosocial or environmental interventions, or behavioural analysis. The NICE guidance suggest that antipsychotic

\section{Box 3 Further information on CADASIL}

- The CADASIL Foundation (www. cadasilfoundation.org), an American site set up by a patient

- CADASIL, a UK site established by Hugh Markus at St George's, University of London (www.sgul.ac.uk/index.cfm?845A33529461-645C-4BED-DF78800E9072)

- The Paris-Munich collaboration on future CADASIL research (www.neurogenetik. de/index.php?id $=8,0,0,1,0,0)$ medication should be used only where there is an immediate risk to others or severe distress is evident. Even then it should be given only to target specific symptoms after a cost-benefit analysis (National Collaborating Centre for Mental Health, 2006; Waldemar et al, 2007). This approach originates from Committee on Safety of Medicines (2004) prescribing advice. Concern arose from a pooled analysis of trials which found increased rates of cerebrovascular events in older people with dementia receiving atypical antipsychotic medication. On the basis of the existing evidence, and taking a more holistic perspective, the Royal College of Psychiatrists is less directive in its advice. It suggests that the clinician 'determine the best balance of risks and benefits for the patient of every possible treatment' (Faculty for the Psychiatry of Old Age, 2006).

\section{Psychosocial interventions}

There may be a role for day care or day hospital involvement with CADASIL patients. Those in the advanced stages of the disease are likely to require specialist nursing care. It is also important to be aware of the significant impact of the disease on carers.

\section{Ethical issues}

The ethical dilemmas are similar to those seen in Huntington's disease, given the autosomal dominant pattern of inheritance in CADASIL. Clinical presentation may not be seen until the individual is beyond childbearing age. Unlike Huntington's however, predictive testing for family members is not well established at a local level. Predictive genetic testing involves significant moral and ethical judgements. The ultimate dilemma faced by affected individuals is whether to have children. Liaison with neurologists and clinical geneticists is important in the management of these families.

\section{Prognosis}

The mean age at death of people with CADASIL has been suggested as $61 \pm 11$ years (range $28-76$ years) with a significant difference between men (55 years, s.d. $=13$ years) and women (66 years, s.d. $=7$ years), $P=0.02$ (Dichgans et al, 1998). There are no consistent indicators of future prognosis in terms of phenotype, although it is hoped that DTI may provide imaging markers when performed at intervals in the course of the disease process. By the time of death, over three-quarters of patients with this progressively debilitating disease are completely dependent on carers (Davous, 1998). 


\section{Conclusions}

CADASIL appears to be more common than previously perceived. The initial presentation of the disorder can be with psychiatric features, though diagnosis may be delayed or missed. It is important to highlight CADASIL to psychiatrists as a potential differential diagnosis, albeit rare, and to stress that the clinical presentation may not appear particularly atypical.

Perhaps as important is the later emergence of psychiatric symptoms in patients with CADASIL. Psychiatrists need to be aware of the condition such that they are able to collaborate with neurologists where there are complex and enduring psychiatric needs, in much the same way as they would for Huntington's or Parkinson's disease.

Further research is needed into optimal methods to diagnose, monitor, and identify potential symptomatic and disease-modifying treatments.

\section{Declaration of interest}

None.

\section{Acknowledgements}

We thank Dr Sumeet Singhal (Specialist Registrar in Neurology, Queen's Medical Centre, Nottingham; formerly of St George's Hospital tertiary CADASIL clinic, London) and Professor Hugh Markus (Professor of Neurology, St George's University of London) for their valuable advice during the preparation of this article.

\section{References}

Alexopoulos, G. S., Meyers, B. S.,Young, R. C., et al (1997) 'Vascular depression' hypothesis. Archives of General Psychiatry, 54, 915922.

Committee on Safety of Medicines (2004) Atypical Antipsychotic Drugs and Stroke: 9 March 2004. Medicines and Healthcare products Regulatory Agency (http://www.mhra.gov.uk/ Safetyinformation/Safetywarningsalertsandrecalls/Safety warningsandmessagesformedicines/CON1004298).

Davies, S. J. C., Jackson, P. R., Potokar, J., et al (2004) Treatment of anxiety and depressive disorders in patients with cardiovascular disease. BMI, 328, 939-943.

Davous, P. (1998) CADASIL: a review with proposed diagnostic criteria. European Journal of Neurology, 5, 219-233.

Desmond, D. W., Moroney, J. T., Lynch, T., et al (1999) The natural history of CADASIL: a pooled analysis of previously published cases. Stroke, 30, 1230-1233.

Dichgans, M., Mayer, M., Uttner, I., et al (1998) The phenotypic spectrum of CADASIL: clinical findings in 102 cases. Annals of Neurology, 44, 731-739.

Dichgans, M., Markus, H. S., et al (2008) Donepezil in patients with subcortical vascular cognitive impairment: a randomised double-blind trial in CADASIL. Lancet Neurology, 7, 310318.

Faculty for the Psychiatry of Old Age (2006) Atypical Antipyschotics and Behavioural and Psychiatric Symptoms of Dementia: Prescribing Update for Old Age Psychiatrists. Royal College of Psychiatrists (http://www.rcpsych.ac.uk/PDF/BPSD.pdf).
Holtmannspotter, M., Peters, N., Opherk, C., et al (2005) Diffusion magnetic resonance histograms as a surrogate marker and predictor of disease progression in CADASIL: a two year follow-up study. Stroke, 36, 2559-2565.

Joutel, A., Vahedi, K., Corpechot, C., et al (1997) Strong clustering and stereotyped nature of notch 3 mutations in CADASIL patients. Lancet, 350, 1511-1515.

Kalaria, R. N., Viitanen, M., Kalimo, H., et al (2004) The pathogenesis of CADASIL: an update. Journal of Neurological Sciences, 226, 35-39.

Kennedy, G. J. \& Marcus, P. (2005) Use of antidepressants in older patients with co-morbid medical conditions: guidance from studies of depression in somatic illness. Drugs and Aging, 22, 273-287.

Kessing, L. V. (2005) Severe brain pathology: underdiagnosed in psychiatric patients? (Invited comment). Acta Psychiatrica Scandinavica, 111, 396-397.

Keverne, J. S., Low, W. C., Ziabreva, I., et al (2006) Cholinergic neuronal deficits in CADASIL. Stroke, 38, 188-191.

Kumar, P. \& Clark, M. (2005) Clinical Medicine (6th edn). Elsevier.

Lagas, P. A. \& Juvonen, V. (2001) Schizophrenia in a patient with cerebral autosomally dominant arteriopathy with subcortical infarcts and leukoencephalopathy (CADASIL disease). Nordic Journal of Psychiatry, 55, 41-42.

Leyhe, T., Wiendl, H., Buchkremer, G., et al (2005) CADASIL: underdiagnosed in psychiatric patients? Acta Psychiatrica Scandinavica, 111, 392-396.

Markus, H. S., Martin, R. J., Simpson, M. A., et al (2002) Diagnostic strategies in CADASIL. Neurology, 59, 1134-1138.

Mesulam, M., Siddique, T. \& Cohen, B. (2003) Cholinergic denervation in a pure multi-infarct state. Neurology, 60, 11831185.

National Collaborating Centre for Mental Health (2006) Dementia: Supporting People with Dementia and Their Carers in Health and Social Care (NICE Clinical Guideline 42). National Institute for Health and Clinical Excellence.

Opherk, C., Peters, N., Holtmannspotter, M., et al (2006), Heritability of MRI lesion volume in CADASIL: evidence for genetic modifiers. Stroke, 37, 2684-2689.

O'Sullivan, M., Jarosz, J. M., Martin, R. J., et al (2001) MRI hyperintensities of the temporal lobe and external capsule in patients with CADASIL. Neurology, 56, 628-634.

Pantoni, L., Pescini, F., Inzitari, D., et al (2005) Postpartum psychiatric disturbances as an unrecognised onset of CADASIL. Acta Psychiatrica Scandinavica, 112, 241.

Razvi, S. S. M., Davidson, R., Bone, I., et al (2005) The prevalence of CADASIL in the West of Scotland. Journal of Neurology, Neurosurgery and Psychiatry, 76, 739-741.

Schon, F., Martin, R. J., Prevett, M., et al (2003) "CADASIL coma": an underdiagnosed acute encephalopathy. Journal of Neurology, Neurosurgery and Psychiatry, 74, 249-252.

Singhal, S., Bevan, S., Barrick, T., et al (2004) The influence of genetic and cardiovascular risk factors on the CADASIL phenotype. Brain, 127, 2031-2038.

Singhal, S., Rich, P. \& Markus, H. S. (2005) The spatial distribution of MR imaging abnormalities in CADASIL and their relationship to age and clinical features. American Journal of Neuroradiology, 26, 2481-2487.

Spalletta, G., Bossa, P., Ciaramella, A., et al (2006) The aetiology of post-stroke depression: a review of the literature and a new hypothesis involving inflammatory cytokines. Molecular Psychiatry, 11, 984-991.

Taylor, D., Paton, C. \& Kerwin, R. (2007) Maudsley Prescribing Guidelines (9th edn). Informa Healthcare.

Verin, M., Rolland, Y., Landgraf, F., et al (1995) New phenotype of the cerebral autosomal dominant arteriopathy mapped to chromosome 19: migraine as the prominent clinical feature. Journal of Neurology, Neurosurgery and Psychiatry, 59, 579-585.

Viswanathan, A., Guichard, J. P., Gschwendtner, A., et al (2006) Blood pressure and haemoglobin A1c are associated with microhaemorrhage in CADASIL: a two-centre cohort study. Brain, 129, 2375-2383.

Waldemar, G., Dubois, B., Emre, M., et al (2007) Recommendations for the diagnosis and management of Alzheimer's and other disorders associated with dementia: EFNS (European Federation of Neurological Science) guideline. European Journal of Neurology, 14, e1-e26. 


\section{MCQs}

1 As a pathological entity, CADASIL:

a is a pure form of white matter ischaemic disease

b is more common than Huntington's disease

c tends not to present at a relatively young age

d rarely follows a course analogous to that of vascular dementia

e may involve disruption to key neural pathways.

2 In terms of the clinical features of CADASIL:

a they tend to be consistent within families

b manic illness is a recognised feature

c migraine is a particularly common symptom in later presentations

d frontal lobe symptoms are unusual

e it is unusual for psychiatric features to be present.

3 In CADASIL diagnosis:

a single photon emission emitted tomography is the first-line neuroimaging investigation

b diffusor tensor imaging is used primarily as a diagnostic tool

c Notch3 mutation screening shows no variance between populations

d family history is unlikely to be relevant

e skin biopsy or genetic testing are legitimate as diagnostic tools.

4 Treatments in CADASIL:

a may include acetylcholinesterase inhibitors in future

b vary significantly from those in vascular dementia c can markedly influence the prognosis

d for secondary prevention exclude antihypertensives, as they are unlikely to be effective

e have an extensive evidence base.

5 As regards psychiatrists and CADASIL:

a for atypical psychiatric presentations consider CADASIL

b psychotropic medication should not be prescribed in CADASIL

c collaboration with neurologists is important

d psychological therapies have been shown to be effective

e there are no significant care giver and social care costs in CADASIL.

\begin{tabular}{|lllllll|}
\hline \multicolumn{2}{|l}{ MCQ answers } & & & & \\
1 & & 2 & 3 & 4 & 5 \\
a T & a F & a F & a T & a F \\
b F & b T & b F & b F & b F \\
c F & c F & c F & c F & c T \\
d F & d F & d F & d F & d F \\
e F & e F & e T & e F & e F \\
\end{tabular}

\section{Night Sister}

How is it possible not to grow hard,

To build a shell around yourself when you

Have to watch so much pain, and hear it too?

Many you see are puzzled, wounded; few

Are cheerful long. How can you not be scarred?

To view a birth or death seems natural,

But these locked doors, these sudden shouts and tears

Graze all the peaceful skies. A world of fears

Like the ghost-haunting of the owl appears.

And yet you love that stillness and that call.
You have a memory for everyone;

None is anonymous and so you cure

What few with such compassion could endure.

I never met a calling quite so pure.

My fears are silenced by the things you've done.

We have grown cynical and often miss

The perfect thing. Embarrassment also

Convinces us we cannot dare to show

Our sickness. But you listen and we know

That you can meet us in our own distress.

Elizabeth Jennings (1926-2001) was born in Boston, Lincolnshire to a medical family. Her father was the Chief Medical Officer. She read English at St Anne's College, Oxford, and later worked as a librarian at Oxford City Library. She was awarded a Commander of the Order of the British Empire (CBE) in 1992. She had a psychiatric hospital admission in the early 1960s and is reported to have attempted suicide. Two volumes of poetry describe her experience of being in a mental hospital, Recoveries (1964) and The Mind has Mountains (1966). 'Night Sister' is reproduced from Elizabeth Jennings: New Collected Poems (ed. M. Schmidt), published by Carcanet. (c) 2002 Estate of Elizabeth Jennings.

Poem selected by Professor Femi Oyebode

doi: 10.1192/apt.14.5.357 